DEPARTMENT OF ECONOMICS WORKING PAPER SERIES

\title{
Secular stagnation and income distribution dynamics
}

\author{
David Kiefer \\ Ivan Mendieta-Muñoz \\ Codrina Rada \\ Rüdiger von Arnim
}

Working Paper No: 2019-05

April 2019

\author{
University of Utah \\ Department of Economics \\ 260 Central Campus Drive \\ Gardner Commons, RM 4100 \\ Tel: (801) 581-7481 \\ http://www.econ.utah.edu
}




\title{
Secular stagnation and income distribution dynamics
}

\author{
David Kiefer \\ Department of Economics, University of Utah. \\ Email: kiefer@economics.utah.edu \\ Ivan Mendieta-Muñoz \\ Department of Economics, University of Utah. \\ Email: ivan.mendietamunoz@utah.edu \\ Codrina Rada \\ Department of Economics, University of Utah. \\ Email: rada@economics.utah.edu \\ Rüdiger von Arnim \\ Department of Economics, University of Utah. \\ Email: rudiger.vonarnim@economics.utah.edu
}

\begin{abstract}
This paper contributes to the literature on secular stagnation by estimating a measure of potential output growth for the post-war US economy derived from a novel model specification that allows for the cyclical interactions between income distribution, represented by the trajectory of the labor share of income, and economic activity, as measured by capacity utilization. The results obtained show that potential output growth exhibits a gradual decline that predates the Great Recession and follows the downward trajectory of the labor share of income, thus suggesting the existence of an important long-run relationship between income distribution and output growth in the USA.
\end{abstract}

Keywords: Potential output growth, capacity utilization, income distribution, labor share, US economy.

JEL Classification: B50, E12, E25, O40.

Acknowledgements: We thank Korkut Ertürk and seminar participants at the University of Utah for helpful suggestions and conversations. Any remaining errors are the responsibility of the authors. 


\section{Introduction}

The slow recovery and overall anemic macroeconomic performance of the US economy following the Great Recession has renewed the debate on the possibility of secular stagnation, that is, an era characterized by a slowdown in the rate of growth of potential GDP. ${ }^{1}$ Skepticism about the long run strength of the US economy remains despite currently low rates of unemployment and fast growth, which topped 4 percent in the second quarter of $2018 .^{2}$ In fact, both the literature and Congressional Budget Office estimates suggest that the decline in potential output growth has been gradual and began before the Great Recession. Further, by definition, potential output growth is an unobservable variable, and its estimation is surrounded by considerable uncertainty: any measure of potential output growth needs to be derived from a model specification that reflects the ongoing controversies about the nature of economic fluctuations. Inherent to such an exercise are difficulties related to how potential output is conceptualized, including the assumptions of the model and the quality of the data. ${ }^{3}$

This paper explicitly explores the idea that income distribution and economic growth share important long-run properties. Our approach is closely related to the macroeconomic literature that considers growth and distribution to be endogenously linked both in the short- and longrun. Following this literature, we study the evolution of a measure of potential output growth derived from a novel model specification that builds on the interactions between income distribution, measured by the labor share, and capacity utilization, defined as the difference between actual and potential output.

\footnotetext{
${ }^{1}$ Larry Summers has been credited to revive the topic, see Summers (2014). In this speech, and in subsequent debate, the focus lies on the low "natural rate of interest", at which, in Wicksellian fashion, investment and savings equilibrate to generate full employment. We do not see historically low long-term interest rates, or the long decline in nominal and real interest rates as a relevant causal factor. At best, it is a symptom of stagnation; and hence our discussion will not focus on it. Teulings and Baldwin (2014) provide a comprehensive discussion of the relevant issues; see as well the next section for further discussion.

${ }^{2}$ Real interest rates at historically low levels, large fiscal deficits, and an unusual buoyant stock market coupled with rising private debt have been fueling recent growth, but also the skepticism about its sustainability as these conditions are unlikely to be maintained indefinitely (Summers 2018).

${ }^{3}$ While we do not want to pursue an ontological discussion about the nature of unobservable variables, it is clear that concepts such as potential output or Total Factor Productivity are theory-dependent (Felipe and McCombie 2007). Therefore, interpretations should be made with caution and only in the context of the theory applied.
} 
The measure of potential output growth constructed in this way is broadly in line with the main findings of the current literature that has studied the trajectory of other conceptualizations of potential output. The central features are that potential output growth exhibits a gradual decline that predates the Great Recession, rather than a sharp and sudden change in trend triggered by the 2008 financial crisis, which coincides with the downward trajectory of the labor share of income. These results suggest the existence of a long-run relationship between the downward trend in the labor share of income and the loss of potential output growth during the post-war period in the USA. Importantly, the empirical model put forth here raises the question whether the rise in inequality as measured by the labor share could be a causal factor for stagnation in the long run, conditional on the short run interaction between growth and distribution.

The remainder of this paper is organized as follows. The next section reviews relevant literature that is related to the present contribution. Section 3 presents the empirical modelling approach adopted. Subsequently, Section 4 presents and discusses the main results. Section 5 concludes.

\section{Literature review and discussion}

The question how income distribution affects overall economic growth has been studied widely, and in different strands of literature. We begin by briefly surveying selected empirical results and the recent surge in neoclassical and new-Keynesian research. Subsequently, we address the Congressional Budget Office's (CBO) efforts to estimate potential output growth. The section concludes with a consideration of the issues from post-Keynesian and classical perspectives.

Selected empirical contributions are Persson and Tabellini (1994), who find a significant and negative relationship between inequality (measured by the income share of the top 20\%) and the annual growth rate of GDP; and Mo (2000), who also finds negative effects of income inequality on the GDP growth rate. Barro (2000) concludes that the effect of income inequality on economic growth depends on the state of economic development: income inequality in poor countries affects negatively economic growth, but income inequality in rich countries affects it positively. By contrast, Forbes (2000) finds a positive effect of a country's level of income inequality on growth considering only the short- and medium-run for a panel of countries; and 
Partridge (2005) and Frank (2009) find a positive long-run association between inequality and growth for the US states.

More recently, however, rising inequality in the personal income distribution and a downward trend in the labor share of income have been extensively documented (e.g., Autor et al. 2017; Elsby et al. 2013; Karabarbounis and Neiman 2013; Piketty and Saez 2003; IMF 2017), and prompted the new-Keynesian macroeconomic literature to consider inequality as a possible explanatory factor for the decline in potential output growth. For example, the overlapping generations model developed by Eggertson and Mehrotra (2014) suggests that a rise in inequality either across or within generations as well as labor market polarization can cause stagnation. However, in this paper (and related research), stagnation tends to be characterized by a negative real interest rate: a rise in inequality increases savings, and full employment savings-investment equilibrium would require negative real interest rates.

According to that view, stagnation arises because monetary policy might be ineffective to bring about sufficiently negative real rates. Conventional Keynesian wisdom suggests that authorities are "pushing on a string", and instead should pursue fiscal expansion. The new-Keynesian literature has begun to rediscover these insights-i.e., at the zero-lower bound, fiscal multipliers are large (Woodford, 2011; Blanchard and Leigh, 2013); and debt has negligible costs (Blanchard, 2019). However, despite the concerns stated in Summers (2014) about the implications of inequality for demand, aggregate demand proper remains an afterthought in the new-Keynesian framework.

Our paper is also related to different ways in which potential output has been computed. One route builds on growth accounting à la Solow. The Congressional Budget Office (CBO) expends considerable effort to do this, see for example CBO (2001). The procedure seeks to estimate potential output based on a Cobb-Douglas production function, with the potential labor force, capital services and TFP as input variables. The potential labor force is obtained by removing cyclical variation (piecewise linear from peak-to-peak) via Okun's Law, with a standard NAIRU as benchmark. As one would expect, the $\mathrm{CBO}$ estimates closely track our findings. However, the hypothesized mechanisms embedded in the estimations are very different. In contrast to Friedman's dictum - that a theory should be judged on its ability to predict, rather than the 
realism of its assumptions-we maintain that the postulated mechanism matters greatly. Predictive powers may be sufficient in some contexts, but they are inadequate as a test for a theory, and cannot inform policy. Crucially, the CBO's approach implicitly assumes a clearing labor market and on average full employment of factors. Our approach is not built on similarly unrealistic assumptions.

An important element in the $\mathrm{CBO}$ approach is that, despite the long-run decline in the natural rate of unemployment, potential output growth has declined as well. This must be due to either a decline in the potential labor force, or Total Factor Productivity (TFP), or both (assuming that capital services come forth as required). An aging workforce plays some role in the former, but the robust finding that the slowdown in potential growth precedes the crisis as well as the onset of retirement of baby boomers suggests that there is more to it than that. Indeed, the CBO has recognized the possibility of hysteresis effects on potential growth (see, for example, CBO 2014, p. 6), but these remain situated on the supply side, and unrelated to insufficient demand and/or rising inequality. Of course, the crux of the matter lies with lackluster TFP (or labor productivity growth) which is an unexplained residual in the CBO's standard growth accounting framework.

Storm (2017) discusses a more promising mechanism, built around the idea that potential TFP growth is in fact a function of actual labor productivity growth. In turn, labor productivity growth responds to economic activity through the so-called Kaldor-Verdoorn channel that highlights the role of economies of scale; and to income distribution through the induced technical change channel that emphasizes the profit maximizing behavior of firms (Naastepad and Storm, 2012). A decline in both economic activity and the labor share would explain a permanent decline in labor productivity growth and therefore the decline in potential output growth. ${ }^{4}$

\footnotetext{
${ }^{4} \mathrm{~A}$ fairly rich literature criticizing the standard growth accounting approach points out that TFP growth is, by definition, a weighted average of real wage and profit rate growth rates where the weights are the factor income shares (Felipe and McCombie 2003, Rada and Taylor 2006). At the steady-state where the profit rate is assumed to be constant, this relation simplifies to an identity between TFP growth and the product of the steady-state labor share and the growth rate of the real wage. If the real wage declines but the labor share remains constant, lower labor productivity growth translates into a decline in TFP growth, and subsequently a decline in potential output. Based on such arguments, Storm (2017) observes that TFP growth provides no additional analytical insight. However, this relationship is based on an accounting identity, and does not identify direction of causality.
} 
We do not introduce such a link from distributive variables to potential growth explicitly. However, the present paper should be seen as a step in that direction, since our main frame of reference is the post-Keynesian and classical literature on the linkages between growth and distribution. For the purposes of this review and the motivation of our empirical model, two distinct strands of the literature should be emphasized.

First, classical writings and the Cambridge equation suggest that in a long-period equilibrium, the rate of accumulation is constrained by the rate of profit. If the rate of capacity utilization and the ratio of full capacity output to capital are constant, the rate of expansion of the system moves in the same direction as the profit share. In other words, in the long-run, growth is facilitated by the available surplus. Goodwin (1967) presents an important formalization of this approach. This growth cycle features a perpetual "predator-prey" oscillation between the labor share and the employment rate around a steady state at which the accumulation rate is equal to the profit rate and the natural growth rate. A distributive shock would affect the steady state employment rate adversely, while steady state labor share and natural growth rate are determined by the exogenous forces of labor supply growth and labor productivity growth. However, the cyclical expansion is driven by the profit share, and in this sense (and much-abused parlance), economic activity would be "profit-led." A central weakness of the classical growth cycle is that it does not give a role to the principle of effective demand.

Second, a large literature building on Keynesian and Kaleckian ideas has sought to formalize a growth model that features the paradox of costs: while wages are costs to individual capitalists, they collectively represent a source of demand. Hence, and in sharp contrast to the classical approach, growth in the long run can be fostered through redistribution towards wage earners. This approach has been criticized for considering the labor share as exogenous even in empirical approaches. Further, neo-Kaleckians have not proposed a convincing mechanism to explain how the economy attains a long-period equilibrium with a constant income-capital ratio and retains a long-run effect of aggregate demand on growth (Lavoie 1996, Skott 2012).

Barbosa-Filho and Taylor (2006) advanced a synthesis of sorts, suggesting to replace the employment rate with a demand-determined income-capital ratio as the state variable to pair with the labor share. Their empirical findings, confirmed subsequently in a variety of studies, 
suggest that at business cycle frequency, economic activity is profit-led, and the reserve army of labor exerts profit-squeeze pressure. ${ }^{5}$ While these results are important, the present paper is agnostic about short run dynamics: we introduce neither a strong theoretical prior, nor focus the discussion on short run results. Instead, our target is the estimation of the underlying potential growth rate conditional on the labor share. Following Blecker (2016), we recognize that the labor share and economic activity might be positively linked in the long run. Kotz and Basu (2019) present a related argument, based on the theory of Social Structures of Accumulation (SSA). The authors outline that periods of growth are fostered by "mutually reinforcing, expansionpromoting institutions", which need to generate both the required profits for continued accumulation as well as a sufficient wage fund to support aggregate demand. Their empirical findings provide suggestive evidence on the linkages between inequality and the current, protracted growth slowdown, and we will return to it further below.

Our approach places emphasis on the growth rate. The emphasis in some of the abovementioned literature on the rate of capacity utilization (or income-capital ratio, as proxy) is, regarding the present purposes, unwarranted. For example, after a crisis, the rate of utilization of a representative firm (or the aggregate output gap) might return quite rapidly to "normal," all the while the potential or natural rate of growth features strong downward hysteresis. Thus, our contribution is also related to that of Li and Mendieta-Muñoz (2018), who focus on the evolution of the natural growth rate. Applying the first difference version of Okun's law to the G-7 countries, they find that the latter exhibits a gradual decline that predates the Great Recession and that is mainly associated with a fall in the productivity growth component. ${ }^{6}$

\footnotetext{
${ }^{5}$ See Mohun and Veneziani (2008), Zipperer and Skott (2011) and Kiefer and Rada (2015), among others, on these short-run dynamics. Flaschel $(2009 ; 2015)$ and Tavani et. al. (2011) provide related discussions. Barrales and von Arnim (2017) extend that investigation on the basis of wavelet decompositions, and find evidence for a bidirectional Granger causality relationship between the labor share and measures of economic activity at high and low frequencies. Kiefer and Rada (2015) provide suggestive evidence of stagnation with falling labor shares and rising output gaps.

${ }^{6}$ Their results corroborate the recent literature on the fall in potential output growth, based on different econometric techniques and conceptualizations of potential output. See, for example, the dynamic factor model used by AntolinDiaz et al. (2017), the alternative Solow-style growth accounting decomposition employed by Fernald et al. (2017), and the decomposition analyses based on the Kalman filter smoothing developed by Gordon (2016).
} 
In summary, the empirical approach outlined in the next section targets a question currently of central importance: conditional on business cycle dynamics between the labor share and the rate of capacity utilization, is there a long run relationship between the labor share and the rate of potential output growth?

\section{Empirical strategy}

As a first step, consider Figure 1 below. This Figure shows the CBO's measure of potential output growth and the trajectory of the labor share for the US nonfarm business sector.

\section{(INSERT FIGURE 1 ABOUT HERE)}

It is possible to observe that both series show a downward trend during the post-war period. The correlation coefficient between these two series is approximately 0.68 and is statistically significant at the $1 \%$ level. This represents preliminary evidence of a statistical relationship between potential output growth and the labor income share.

Our empirical approach consists in considering a specification of the Goodwin model that explicitly incorporates the interactions between income distribution, measured by the labor share $\left(\psi_{t}\right)$, and economic activity, measured by capacity utilization $\left(v_{t}\right)$ as the difference between the natural log of actual output $\left(y_{t}\right)$ and the natural log of potential output $\left(y_{t}^{*}\right): v_{t}=y_{t}-y_{t}^{*}$. The specification of this model is agnostic in that it does not specify a theoretical prior, but merely conditions the estimation of potential growth on business cycle interaction of labor share and the rate of capacity utilization. Specifically, we follow the Vector Autoregressive model of order 2 proposed by Rada and Kiefer (2016) that captures the dynamic interactions between $\psi_{t}$ and $v_{t}:$

$$
\begin{gathered}
\psi_{t}=\alpha_{0}+\alpha_{1} \psi_{t-1}+\alpha_{2} v_{t-1}+\alpha_{3} \psi_{t-2}+\alpha_{4} v_{t-2}+\varepsilon_{\psi, t} \\
v_{t}=\beta_{0}+\beta_{1} \psi_{t-1}+\beta_{2} v_{t-1}+\beta_{3} \psi_{t-2}+\beta_{4} v_{t-2}+\varepsilon_{v, t}
\end{gathered}
$$


where $\alpha_{i}$ and $\beta_{i}, i=0,1,2,3,4$, are coefficients to be estimated; and $\varepsilon_{\psi, t} \sim$ iid. $N\left(0, \sigma_{\psi}^{2}\right)$ and $\varepsilon_{v, t} \sim$ iid. $N\left(0, \sigma_{v}^{2}\right)$ represent the stochastic disturbances that satisfy the standard statistical properties. $^{7}$

We then embed a dynamic characterization of potential output into the VAR(2) of distribution and utilization depicted in equation (1). We assume that the rate of growth of potential output $\left(g_{t}^{*}\right)$ follows a random walk:

$$
g_{t}^{*}=g_{t-1}^{*}+\varepsilon_{g, t} \quad \ldots \ldots \ldots
$$

where $\varepsilon_{g, t} \sim$ iid. $N\left(0, \sigma_{g}^{2}\right)$ represents the stochastic disturbance; and that $\operatorname{cov}\left(\varepsilon_{g, t}, \varepsilon_{\psi, t}\right)=$ $\operatorname{cov}\left(\varepsilon_{g, t}, \varepsilon_{v, t}\right)=0$, so that the shocks to the potential rate of growth are independent of the shocks in equation (1).

The choice of the dynamics of the growth rate of potential output $g_{t}^{*}$ in equation (2) is based on the standard specification of unobserved state variables in state-space models - see also Appendix A.1 for a more comprehensive discussion of the technical details, but it can also be intuitively motivated. First, by assuming that $g_{t}^{*}$ follows a random walk we leave unconstrained the growth rate of potential output (with the exception of the standard normality assumptions). This "lets the data speak" on the trajectory of potential growth, conditional on the dynamic interaction of the observables $\psi_{t}$ and $y_{t}$. Second, since we are interested in capturing the evolution of long-run output growth rates by considering frequencies lower than the business cycle, the random walk assumption allows us to capture those changes in output growth that have been of permanent nature - that is, non-mean-reverting changes.

Therefore, the level of potential output can be defined recursively:

$$
y_{t}^{*}=y_{t-1}^{*}+g_{t}^{*} \quad \cdots \cdots \cdots
$$

And, substituting equation (3) into the definition of $v_{t}$ we have that:

$$
v_{t}=y_{t}-y_{t}^{*}=y_{t}-\left(y_{t}^{*}+g_{t}^{*}\right) \quad \cdots \cdots \cdots
$$

\footnotetext{
${ }^{7}$ Empirically, we found that a $\operatorname{VAR}(2)$ captures the basic dynamics better than a $\operatorname{VAR}(1)$, and that little is added if we consider a $\operatorname{VAR}(3)$.
} 
Finally, substituting equations ( 3 ) and (4) into the original $\operatorname{VAR}(2)$ shown in equation (1) yields:

$$
\begin{gathered}
\psi_{t}=\alpha_{0}+\alpha_{1} \psi_{t-1}+\alpha_{2}\left(y_{t-1}-y_{t-1}^{*}\right)+\alpha_{3} \psi_{t-2}+\alpha_{4}\left(y_{t-2}-y_{t-2}^{*}\right)+\varepsilon_{\psi, t} \\
y_{t}=y_{t-1}^{*}+g_{t}^{*}+\beta_{0}+\beta_{1} \psi_{t-1}+\beta_{2}\left(y_{t-1}-y_{t-1}^{*}\right)+\beta_{3} \psi_{t-2}+\beta_{4}\left(y_{t-2}-y_{t-2}^{*}\right)+\varepsilon_{v, t}
\end{gathered}
$$

The VAR(2) model shown in equation (5) contains two unobserved state variables, $g_{t}^{*}$ and $y_{t}^{*}$, and two observed variables, $\psi_{t}$ and $y_{t}$, and as such defines a linear state-space model that, via the Kalman filter, can provide an estimate of $g_{t}^{*}$.

State-space models typically deal with dynamic time series models that involve unobservable variables. Such models consist of a measurement equation, which describes the relationship between observed variables and unobserved state variables, and a transition state equation, which describes the dynamics of the state variables. In our empirical model, equations (2) and (3) represent the state transition equations and the two equations in (5) depict the measurement equations. In the next section we show the estimates of the unobserved state variables and the model's unknown parameters obtained from the Kalman filter and the sample log-likelihood function based on the prediction error decomposition. ${ }^{8}$

\section{Results}

The model represented by equations (2), (3) and (5) was estimated using annual data for the US nonfarm business sector for the period 1947-2016 and for the US nonfinancial corporate business sector for the period 1948-2015. For the latter, we considered two different measures of $\psi_{t}$ : an unadjusted $\psi_{t}$, calculated as the ratio of compensation of employees relative to corporate net value added; and an adjusted $\psi_{t}$, which excludes the top $1 \%$ of the wage and salary distribution. ${ }^{9}$

\footnotetext{
${ }^{8} \mathrm{~A}$ technical description of state-space models, the Kalman filter and the log-likelihood function is presented in Appendix A.

${ }^{9}$ Data on the labor share and output of the Nonfarm Business sector comes from Bureau of Labor Statistics, "BLS_dataset_annualseries2017", and reflects the press release of September 7, 2017. Data for labor share and output of the Nonfinancial Corporate Business sector comes from the Bureau of Economic Analysis, National Income and Product Accounts, Table 1.14 released on February 28, 2018. The labor share is calculated as the ratio of nominal compensation of employees (line 20; i.e. including wages and salaries and supplements) and net value added (line 129). Output is measured as Real Net Value Added and is calculated as the difference between the Gross Value Added and Consumption of Capital; and it can be found on line 43 in Table 1.14. The adjusted labor share for the Nonfinancial Corporate Business sector seeks to proxy the portion of wages that are truly labor income, but include CEO and superstar "salaries." Hence, it excludes the top 1\% of the wage distribution (Piketty and Saez 2003). For details on this adjustment, see Barrales and von Arnim (2017, p. 201).
} 
Following Kim and Nelson (1999), in all estimations we corroborated the appropriateness of the specified models checking for the lack of serial correlation (using the Ljung-Box $Q$ test); homoskedasticity (using an ARCH test for heteroskedasticity); and normality (using the JarqueBera normality test) in the standardized one-period-ahead-forecast errors of the different estimations. ${ }^{10}$ Table B.1 in Appendix B presents the estimated coefficients for the respective models, which shows. It can be ascertained that the majority of the relevant parameters are of similar magnitude and also present similar levels of statistical significance. ${ }^{11}$

The two estimated models for the US nonfinancial corporate business sector satisfied the properties of no serial correlation, homoskedasticity and normality at the $95 \%$ level of confidence. On the other hand, the estimated model for the US nonfarm business sector did not present problems of serial correlation at the $90 \%$ level and satisfied the properties of homoskedasticity and normality at the $95 \%$ level. Overall, the estimations of the different models suggest no evidence of model misspecification. ${ }^{12}$

The estimated $g_{t}^{*} s$ are presented in Figures 1 and 2 below. All figures show the smoothed estimates of the measures of potential output growth, together with their respective $95 \%$ confidence intervals, the actual growth rates, and the rates of growth of potential output estimated by the CBO. The CBO's potential output growth rates lie within our estimated $95 \%$ confidence intervals during the periods of study.

\section{(INSERT FIGURE 2 ABOUT HERE)}

\section{(INSERT FIGURE 3 ABOUT HERE)}

\footnotetext{
${ }^{10}$ To initialize the Kalman filter, the priors for the mean and variance of the $g_{t}^{*} s$ were the following: $3.61 \%$ and 1.09 for the nonfarm business sector, respectively; $4.38 \%$ and 1.60 for the nonfinancial corporate business sector using the unadjusted labor share, respectively; and $4.34 \%$ and 0.56 for the nonfinancial corporate business sector using the adjusted labor share, respectively. These values correspond to the estimated moments of the $g_{t}^{*}$ s obtained from a first Kalman filter estimation. Finally, in all cases we stipulated that the standard deviation of the potential output growth rate was 0.5 (that is, $\sigma_{g}=0.5$ ) to allow for rather larger shocks to potential output growth.

${ }^{11}$ The signs of parameters (and hence their economic interpretation) that reflect cyclical dynamics are also in line with previous findings by Barbosa and Taylor (2006), which we invite the reader to consult. Our focus here is, however, on estimating potential output conditional on the dynamic between economic activity and the labor share. ${ }^{12} \mathrm{~A}$ full report with specification tests for all models-here and further below-is available upon request.
} 
The CBO's measure of potential output growth has fallen from approximately $5.3 \%$ in 1950 to $1.8 \%$ in 2016, which represents a fall of approximately -3.5 percentage points. The estimates of $g_{t}^{*}$ indicate that potential output growth has decreased from approximately $3.7 \%$ in 1947 to $1.7 \%$ in 2016 in the nonfarm business sector (-2 percentage points), from approximately 4.4\% in 1948 to $1.3 \%$ in 2015 (-3.1 percentage points) in the nonfinancial corporate business sector when the unadjusted labor share was used, and from approximately 4.3\% in 1948 to $1.5 \%$ in 2016 (-2.8 percentage points) in the nonfinancial corporate business sector when the adjusted labor share was used.

However, a closer inspection of Table B.1 reveals one potentially problematic result related to the persistence of the shocks. The estimates of the autoregressive coefficients of the labor share equations for the nonfarm business sector and for the nonfinancial corporate business sector using the unadjusted labor share sum up to 1.07 and 1.15, respectively. This suggests the possible presence of unit roots in the labor shares, which is further corroborated by different unit root tests that show that both measures of the labor share are integrated series of order 1.

Although the maximum likelihood estimation procedure is not affected by the presence of unit roots, as a robustness check we corroborated if the smoothed $g_{t}^{*}$ s estimates change when we consider stationary $\psi_{t}$ series. Hence, in order to remove the stochastic trend, we considered the first differences of the labor share, $\Delta \psi_{t}$, in the measurement equations for the nonfarm business sector and the nonfinancial corporate business sector when the unadjusted labor share was used:

$$
\begin{gathered}
\Delta \psi_{t}=\gamma_{0}+\gamma_{1} \Delta \psi_{t-1}+\gamma_{2}\left(y_{t-1}-y_{t-1}^{*}\right)+\gamma_{3} \Delta \psi_{t-2}+\gamma_{4}\left(y_{t-2}-y_{t-2}^{*}\right)+\varepsilon_{\Delta \psi, t} \\
y_{t}=y_{t-1}^{*}+g_{t}^{*}+\zeta_{0}+\zeta_{1} \Delta \psi_{t-1}+\zeta_{2}\left(y_{t-1}-y_{t-1}^{*}\right)+\zeta_{3} \Delta \psi_{t-2}+\zeta_{4}\left(y_{t-2}-y_{t-2}^{*}\right)+\varepsilon_{v, t}^{\prime}
\end{gathered}
$$

The estimated coefficients of the alternative state-space model defined by equations (2), (3) and (6) is presented in Table B.2 in Appendix B.

The estimation results for the US nonfinancial corporate business sector satisfy all correct specification tests at the $95 \%$ level, while the results for the nonfarm business sector do not show evidence of serial correlation at the $90 \%$ level and do not present problems of heteroskedasticity or non-normality at the $95 \%$ level. Moreover, the coefficients obtained are fairly similar and also present similar levels of statistical significance. 
Finally, the smoothed estimates of $g_{t}^{*} s$ are presented in Figures 4 and 5 below, together with their respective 95\% confidence intervals, the actual growth rates and the CBO's measure of potential output growth.

\section{(INSERT FIGURE 4 ABOUT HERE)}

\section{(INSERT FIGURE 5 ABOUT HERE)}

The estimates of $g_{t}^{*}$ closely track results discussed above. The new estimations show that potential output growth has decreased from approximately 3.2\% in 1948 to $2.1 \%$ in 2016 in the nonfarm business sector (a fall of -1.1 percentage points), and from approximately $4.6 \%$ in 1949 to $1.5 \%$ in 2015 in the nonfinancial corporate business sector when the unadjusted labor share was used (which represents a fall of -3.1 percentage points). Therefore, the results obtained using either $\psi_{t}$ or $\Delta \psi_{t}$ yield similar results: a gradual decline in potential output growth that predates the Great Recession and that follows the downward trend of the labor share of income.

\section{Conclusions}

This paper assumes that economic growth and income distribution share important long run properties. In this way, secular stagnation in the USA, represented by the gradual decline in potential output growth, is related to the worsening trend in income inequality, represented by the downward trajectory of the labor share of income. We estimate potential output growth in a dynamic model that explicitly considers the dynamic interaction between the labor share of income and capacity utilization. This starting point differentiates our approach from others in the literature such as the CBO's. Two features of our approach are particularly appealing: the endogenous treatment of both income distribution and economic activity; and the simultaneous analysis of trends and business cycles. As expected, our results are roughly in line with the CBO's estimate of the rate of potential growth. Nevertheless, in contrast to the CBO framework, our approach brings the socio-economic conflict over the distribution of income to the fore, through the endogenization of the labor share.

In summary, the results obtained for the nonfarm business sector and the nonfinancial corporate business sector for the post-war period show a gradual decline of the measure of potential 
output growth that predates the Great Recession. Hence, our results confirm previous findings in the literature on the fall of potential output growth in a new framework. Our findings clearly indicate a positive long run relationship between economic growth and the labor share in the post war US economy, conditional on the theoretical framework put forth. A relevant implication of our exercise is that income distribution should be an integral part of the investigation of specific mechanisms that explain stagnation. Future research should further investigate whether slower growth is depressing the labor share in the long run, or vice versa, and provide a more disaggregated characterization of the channels that connect both phenomena.

For now, we briefly consider several mechanisms of stagnation in a distribution-growth framework. Our starting point is that the stylized picture drawn up in Goodwin (1967) matters greatly, and has been confirmed by the subsequent empirical literature: cyclical expansions at business cycle frequency are profit-led. How do we square this with the positive long run relation between the labor share and potential growth? Several possibilities arise.

First, business cycles evolve around a shifting equilibrium: shocks to exogenous variables alter the steady state of the model. This possibility is raised by Kiefer and Rada (2015). Put simply, decreases in the labor share (through globalization, financialization and technical change) should lead to an acceleration of economic activity, but haven't. As Blecker (2017) points out, the empirical record would make sense if structural austerity depressed demand. However, this channel might be implausible, given high fiscal deficits and very loose monetary policy throughout much of the recent period.

A second mechanism could be drawn up on the basis of explicit treatment of expectations. The Goodwin model's lower turning point is provided by the falling labor share. That, in the original supply-constrained version with a fixed income-capital ratio, triggers the increase in investment. However, in a demand-driven version-à la Flaschel (2009; 2015) or Barbosa and Taylor (2006)the decline in real unit labor costs is only one argument; the other is, of course, the endogenous activity variable. Now, if capitalists do not expect demand to rise, the labor share could fall to zero, and investment would still not come forth. In other words: suppose capitalists observe a weakening profit squeeze, technological unemployment, and the increasingly precarious lives of 
their customers. Would they conclude that expansion of capacity is not warranted, even at falling labor costs? This, of course, would imply that long run growth is wage constrained.

A third hypothesis focuses on induced technical change. If technological progress is strongly driven by increases in real unit labor costs, labor suppression and the resulting fall in the labor share might be a causal factor in the weakening of labor productivity growth (Naastepad and Storm, 2012). Long run growth would again be wage-constrained-but along the lines of MarxVerdoorn, rather than expectations about demand. If the growth rate of labor productivity responds positively to the labor share through induced technical change, rising inequality would lead to high employment rates and a decline in the potential or natural rate of growth. In this manner, our results might be consistent with a classical growth cycle and the institutional and empirical analyses proposed by Montier and Pilkington (2017) and Kotz and Basu (2019).

We believe that these hypotheses deserve further investigation. Based on our analysis, the starting point is that trend output growth and the income distribution are linked positively during recent decades. 


\section{References}

Antolin-Diaz, Juan, Thomas Drechsel and Ivan Petrella. 2017. Tracking the Slowdown in Long-run GDP Growth. Review of Economics and Statistics, 99(2): 343-356.

Autor, David, David Dorn, Lawrence F. Katz, Christina Patterson, and John Van Reenen. 2017. The Fall of the Labor Share and the Rise of Superstar Firms. NBER Working Paper No. 23396

Barbosa-Filho, Nelson H. and Lance Taylor. 2006. Distributive and Demand Cycles in the US Economy -A Structuralist Goodwin Model. Metroeconomica, 57(3): 389-411.

Barrales, Jose and Rudiger von Arnim. 2017. Longer-run Distributive Cycles: Wavelet Decompositions for the US, 1948-2011. Review of Keynesian Economics, 5(2): 196-217.

Barro, Robert J. 2000. Inequality and Growth in a Panel of Countries. Journal of Economic Growth, 5(1): 5-32.

Blanchard, Olivier J. 2019. Public Debt and Low Interest Rates. American Economic Review, 109(4), 1197-1229.

Blanchard, Olivier J. and Daniel Leigh. 2013. Growth Forecast Errors and Fiscal Multipliers. IMF Working Paper 1301.

Blecker, Robert A. 2016. Wage-led Versus Profit-led Demand Regimes: The Long and the Short of it. Review of Keynesian Economics, 4(4): 373-390.

Blecker, Robert A. 2017. Long-term Shifts in Demand and Distribution in Neo-Kaleckian Models with and without Short-run Goodwin Cycles. Mimeo.

CBO. 2001. CBO's Method for Estimating Potential Output: An Update. Congress of the United States: Congressional Budget Office. Available at: https://www.cbo.gov/sites/default/files/107th-congress-20012002/reports/potentialoutput.pdf (accessed July 23, 2018).

2014. Revisions to CBOs Projection of Potential Output Since 2007. Congress of the United States: Congressional Budget Office. Available at: https://www.cbo.gov/sites/default/files/113th-congress-2013-2014/reports/45150PotentialOutput.pdf (accessed July 23, 2018).

Eggertsson, Gauti B., and Neil R. Mehrotra. 2014. A Model of Secular Stagnation. NBER Working Paper No. 20574. Cambridge: National Bureau of Economic Research.

Elsby, Michael W. L., Bart Hobijn, and Ayşegül Şahin. 2013. The Decline of the US Labor Share. Brookings Papers on Economic Activity, 44(2): 1-63.

Felipe, J. and J. S. L. McCombie. 2003. Some methodological problems with the neoclassical analysis of the East Asian miracle. Cambridge Journal of Economics, 27(5): 695-721.

Fernald, John G., Robert E. Hall, James H. Stock, and Mark W. Watson. 2017. The Disappointing Recovery of Output after 2009. Brooking Papers on Economic Activity, 48(1): 1-58.

Flaschel, P. 2009. The Macrodynamics of Capitalism: Elements for a Synthesis of Marx, Keynes and Schumpeter. Berlin: Springer.

. 2015. Goodwin's MKS System: A Baseline Macro Model. Cambridge Journal of Economics, 39(6): 1591-1605 
Forbes, Kristin J. 2000. A Reassessment of the Relationship Between Inequality and Growth. American Economic Review, 90(4): 869-887.

Frank, Mark W. 2009. Inequality and Growth in the United States: Evidence from a New Statelevel Panel of Income Inequality Measures. Economic Inquiry, 47(1), 55-68.

Goodwin, Richard M. 1967. A Growth Cycle, in Socialism, Capitalism and Growth: Essays Presented to Maurice Dobb, edited by Charles H. Feinstein. Cambridge: Cambridge University Press, 54-58.

Gordon, R. 2016. The Rise and Fall of American Growth. Princeton: Princeton University Press.

Karabarbounis, Loukas, and Brent Neiman. 2013. The Global Decline of the Labor Share. Quarterly Journal of Economics, 129(1): 61-103.

Kiefer, David, and Codrina Rada. 2015. Profit Maximizing Goes Global: The Race to the Bottom. Cambridge Journal of Economics, 39(5): 1333-1350.

Kotz, David M. and Deepankar Basu. 2019. Stagnation and Institutional Structures. Review of Radical Political Economy, 51(1): 5-30.

IMF. 2017. Understanding the Downward Trend in Labor Income Shares. World Economic Outlook: Gaining Momentum? Washington, D.C.

Kim, Chang-Jim, and Charles R. Nelson. 1999. State-space Models with Regime Switching. Classical and Gibbs Sampling Approaches with Applications. Cambridge: The MIT Press.

Lavoie, Marc. 1996. Traverse, Hysteresis and Normal Rates of Capacity Utilization in Kaleckian Models of Growth and Distribution. Review of Radical Political Economy, 28(4), 113-147.

$\mathrm{Li}$, Mengheng, and Ivan Mendieta-Muñoz. 2018. Are long-run output growth rates falling? University of Utah. Department of Economics Working Paper Series No. 2018-02.

Mo, Park H. (2000). Income Inequality and Economic Growth. Kyklos, 53(3): 293-315.

Mohun, Simon, and Roberto Veneziani. 2008. Goodwin Cycles and the US Economy, 1948-2004, in Mathematical Economics and the Dynamics of Capitalism: Goodwin's Legacy Continued, edited by Peter Flaschel, and Michael Landesmann. Oxfordshire: Routledge, 157-194.

Montier, James and Philip Pilkington. 2017. The Deep Causes of Secular Stagnation and the Rise of Populism. Advisor Perspectives, GMO. Available at: https://www.advisorperspectives.com/commentaries/2017/03/27/the-deep-causes-ofsecular-stagnation-and-the-rise-of-populism (accessed September 5, 2018).

Partridge, Mark D. 2005. Does Income Distribution Affect U.S. State Economic Growth? Journal of Regional Science, 45(2): 363-394.

Persson, Torsten, and Guido Tabellini. 1994. Is Inequality Harmful for Growth? American Economic Review, 84 (3): 600-621.

Piketty, Thomas, and Emmanuel Saez. 2003. Income Inequality in the United States, 1913-1998. Quarterly Journal of Economics, 118(1): 1-39. (The updated version of the series can be found at: https://eml.berkeley.edu/ saez/ (accessed March 27, 2018)).

Rada, Codrina, and David Kiefer. 2016. Distribution-utilization Interactions: A Race-to-theBottom Among OECD Countries. Metroeconomica, 67(2): 477-498. 
Rada, C. and Taylor, L. (2006). Empty sources of growth and accounting, and empirical replacements a la Kaldor and Goodwin with some beef. Structural Change and Economic Dynamics, 17(4): 486-500.

Skott, Peter. 2012. Shortcomings of the Neo-Kaleckian Investment Function. Metroeconomica, 63(1): 109-138.

Storm, Servaas. 2017. The new normal: Demand, secular stagnation, and the vanishing middle class. International Journal of Political Economy, 46(4): 169-210.

Summers, Lawrence H. 2014. U.S. Economic Prospects: Secular Stagnation, Hysteresis, and the Zero Lower Bound. Business Economics, 49(2): 65-73.

Summers, Lawrence H. 2018. The Threat of Secular Stagnation has not Gone Away. Financial Times, May 16, 2018. Available at: https://www.ft.com/content/aa76e2a8-4ef2-11e89471-a083af05aea7 (accessed August 19, 2018).

Tavani, Daniele, Peter Flaschel, and Lance Taylor. 2011. Estimated Non-linearities and Multiple Equilibria in a Model of Distributive-demand Cycles. International Review of Applied Economics, 25(5): 519-538.

Teulings, Coen, and Richard Baldwin, ed. 2014. Secular Stagnation: Facts, Causes and Cures. London: VoxEU.org eBook, Centre for Economic Policy Research (CEPR) press.

Woodford, Michael. 2011. Simple Analytics of the Government Expenditure Multiplier. American Economic Journal: Macroeconomics, 3(1): 1-35.

Zipperer, Ben, and Peter Skott. 2011. Cyclical patterns of employment, utilization and profitability. Journal of Post Keynesian Economics, 34(1): 25-58. 
Figures

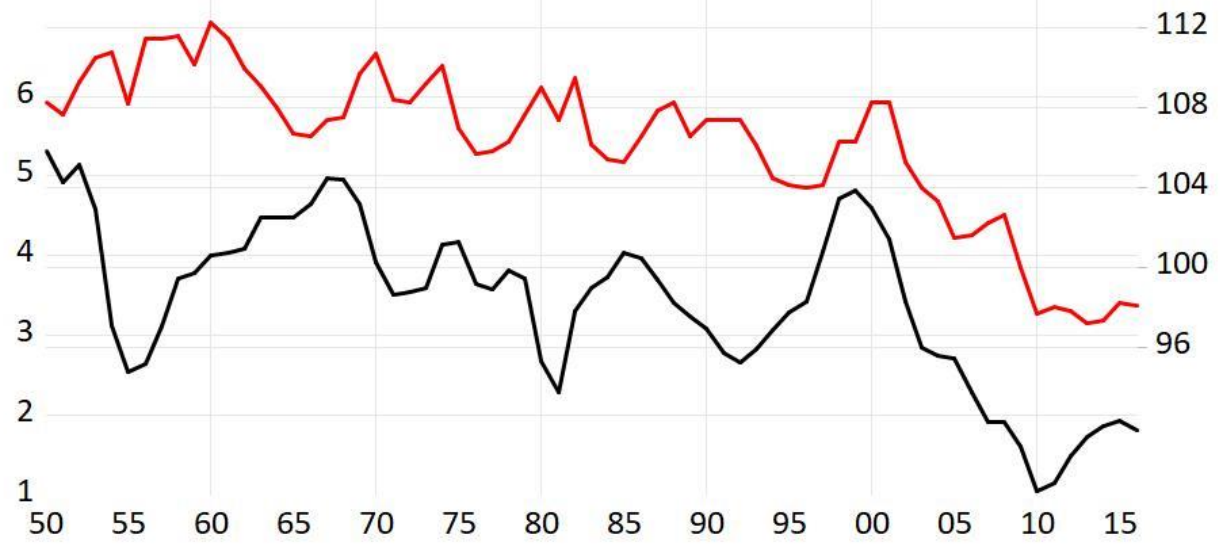

Figure 1. USA, nonfarm business sector, 1950-2016. CBO's potential output growth rate (in percentage, black line, left axis) and labor share (index 2009=100, red line, right axis).

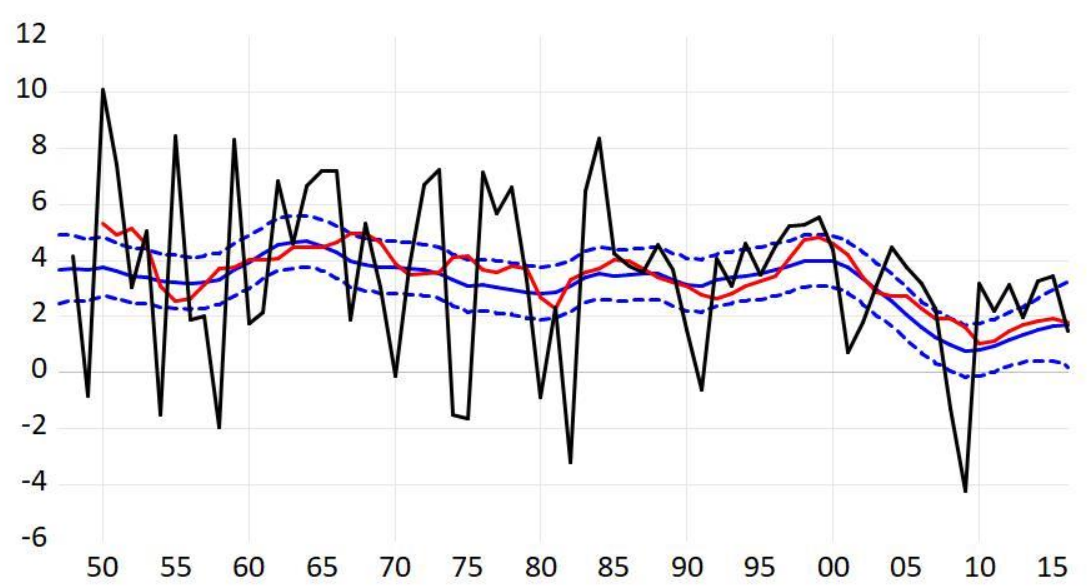

Figure 2. USA, 1947-2016. Estimations of the potential output growth rate for the nonfarm business sector obtained from equations (2), (3) and (5). Smoothed estimates of the potential output growth rate are the blue straight lines. Blue dotted lines represent the $95 \%$ confidence interval around the latter. The Congressional Budget Office (CBO) measure of potential output growth is the red straight line (first observation: 1950). The actual growth rate of the nonfarm business sector output is the black straight line (first observation: 1948). 


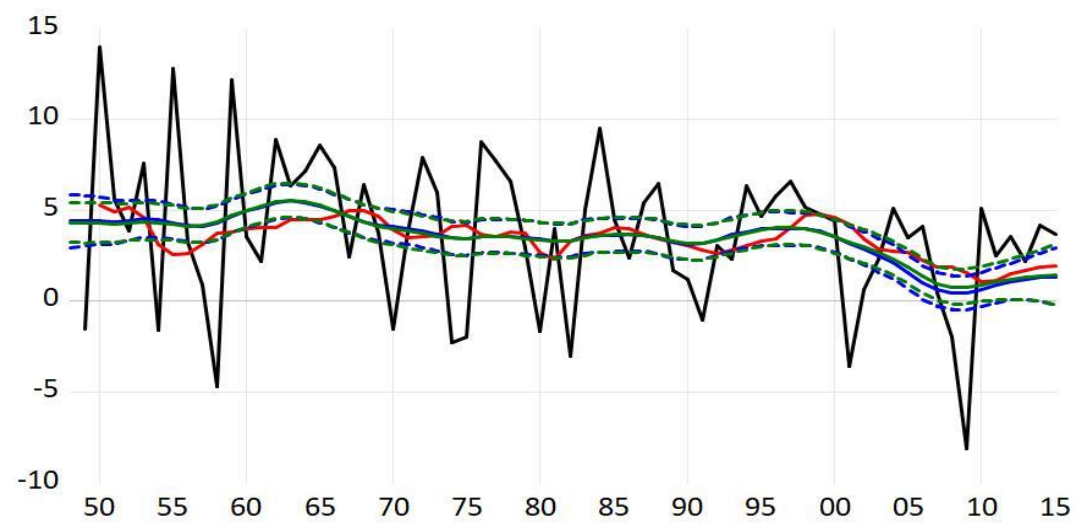

Figure 3. USA, 1948-2015. Estimations of the potential output growth rates for the nonfinancial corporate business sector obtained from equations (2), (3) and (5). Smoothed estimates of the potential output growth rates using the unadjusted labor share and the adjusted labor share are the blue and green straight lines, respectively. Blue and green dotted lines represent $95 \%$ confidence intervals around the latter. The Congressional Budget Office (CBO) measure of potential output growth (for the nonfarm business sector) is the red straight line (first observation: 1950). The actual growth rate of the nonfinancial corporate business sector output is the black straight line (first observation: 1949).

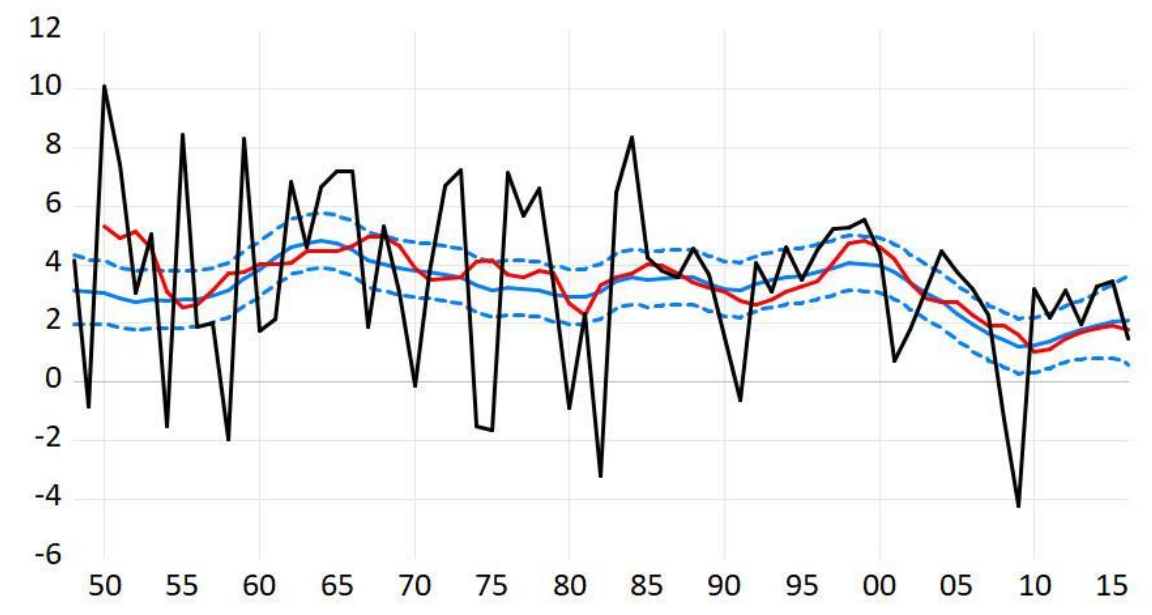

Figure 4. USA, 1948-2016. Estimations of the potential output growth rate for the nonfarm business sector obtained from equations (2), (3) and (6). Smoothed estimates of the potential output growth rate are the blue azure straight lines. Blue azure dotted lines represent the $95 \%$ confidence interval around the latter. The Congressional Budget Office (CBO) measure of potential output growth is the red straight line (first observation: 1950). The actual growth rate of the nonfarm business sector output is the black straight line. 


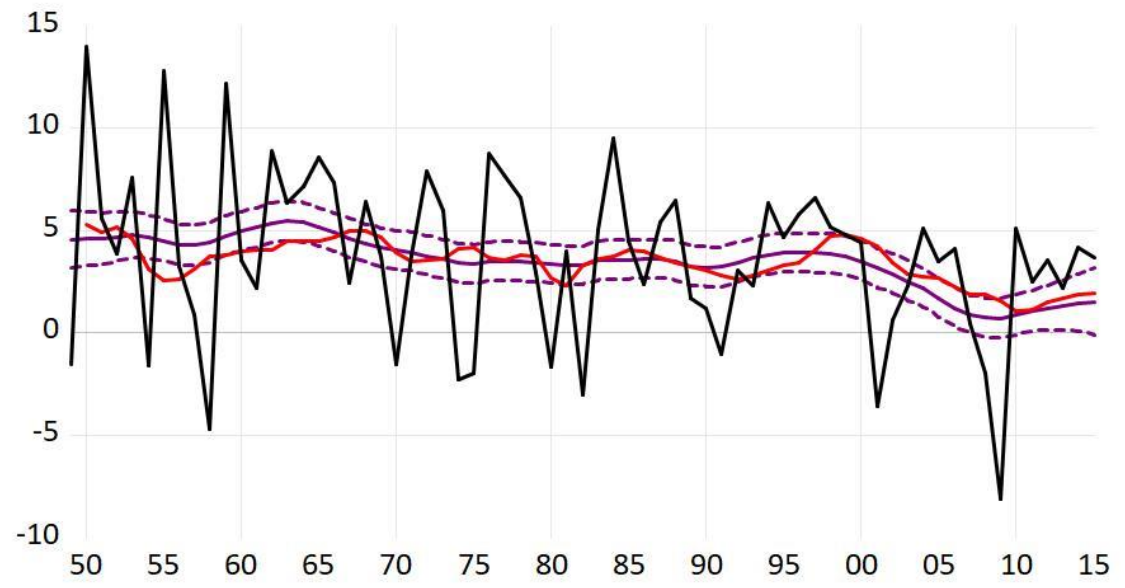

Figure 5. USA, 1949-2015. Estimations of the potential output growth rate for the nonfinancial corporate business sector obtained from equations (2), (3) and (6) using the unadjusted labor share. Smoothed estimates of the potential output growth rate are the purple straight lines. Purple dotted lines represent the $95 \%$ confidence interval around the latter. The Congressional Budget Office (CBO) measure of potential output growth (for the nonfarm business sector) is the red straight line (first observation: 1950). The actual growth rate of the nonfinancial corporate business sector output is the black straight line. 


\section{Appendix A: Econometric details}

This appendix provides details on state-space models, the Kalman filter and the sample loglikelihood function. A state-space model consists of two equations: a transition (or state) equation and a measurement equation. The former describes the relation between the observed variables (data) and unobserved state variables, while the latter describes the dynamics of the state variables and has the form of a first-order difference equation in the state vector.

Following Kim and Nelson (1999), a linear state-space representation of the dynamics of a $n x 1$ vector of variables observed at time $t=1,2, \ldots, T, \mathbf{y}_{\mathbf{t}}$, can be represented by the following system of equations:

$$
\begin{aligned}
& \mathbf{y}_{\mathrm{t}}=\mathbf{H}_{\mathrm{t}} \mathbf{B}_{\mathrm{t}}+\mathbf{A z}_{\mathrm{t}}+\mathbf{e}_{\mathrm{t}} \ldots \ldots \ldots \ldots \text { (A. 1) } \\
& \left.\mathbf{B}_{\mathbf{t}}=\overline{\boldsymbol{\mu}}+\mathbf{F B}_{\mathrm{t}-1}+\mathbf{v}_{\mathrm{t}} \quad \ldots \ldots \ldots \ldots \quad \text { (A. } 2\right) \\
& \left.\mathbf{e}_{\mathbf{t}} \sim \text { iid. } N(0, \mathbf{R}) \quad \ldots \ldots \ldots \ldots \ldots \ldots \text { (A. } 3\right) \\
& \mathbf{v}_{\mathbf{t}} \sim \text { iid. } N(0, \mathbf{Q}) \quad \ldots \ldots \ldots \ldots \ldots \ldots \quad(\text { A. } 4) \\
& E\left(\mathbf{e}_{\mathbf{t}} \mathbf{v}_{\mathbf{s}}^{\prime}\right)=0, \quad \text { for all } s
\end{aligned}
$$

where $\mathbf{B}_{\mathbf{t}}$ is a $k x 1$ vector of unobserved state variables; $\mathbf{H}_{\mathbf{t}}$ is an $n x k$ matrix that links the observed $\mathbf{y}_{\mathbf{t}}$ vector and the unobserved $\mathbf{B}_{\mathbf{t}}$ (elements of which can be either data on exogenous variables or constant parameters); $\mathbf{A}$ is an $n x r$ matrix of coefficients; $\mathbf{z}_{\mathbf{t}}$ is an $r x 1$ vector of exogenous or predetermined observed variables; $\overline{\boldsymbol{\mu}}$ is a $k x 1$ vector; and $\mathbf{F}$ is a $k x k$ matrix of coefficients.

Equations (A.1) and (A.2) represent, respectively, the measurement and the transition equations of a state-space model in which the measurement equation errors, $\mathbf{e}_{\mathbf{t}}$, are independent of the transition equation errors, $\mathbf{v}_{\mathbf{t}}$.

In this representation, the positive-definiteness of $\mathbf{R}$ and $\mathbf{Q}$ is not always guaranteed. A usual practice is to write equations (A.2) and (A.4) alternatively as:

$$
\begin{gathered}
\mathbf{B}_{\mathbf{t}}=\overline{\boldsymbol{\mu}}+\mathbf{F B}_{\mathbf{t}-\mathbf{1}}+\mathbf{G v}_{\boldsymbol{t}}^{*} \quad \ldots \ldots \ldots \ldots \\
\mathbf{v}_{\boldsymbol{t}}^{*} \sim \text { iid. } N\left(0, \mathbf{Q}^{*}\right) \quad \ldots \ldots \ldots \ldots \ldots \ldots
\end{gathered}
$$

where $\mathbf{G}$ is $k x g$; and $\mathbf{v}_{\boldsymbol{t}}^{*}$ is $g x 1(g \leq k)$. This representation of the transition equation guarantees the positive-definiteness of $\mathbf{Q}^{*}$; and the relationship between $\mathbf{Q}$ in equation (A.4) and $\mathbf{Q}^{*}$ in equation (A.7) is given by $\mathbf{Q}=\mathbf{G} \mathbf{Q}^{*} \mathbf{G}^{\prime}$. 
The basic tool to deal with the standard state-space model is the Kalman filter. The latter is a recursive procedure for computing the optimal estimate of the unobserved state vector $\mathbf{B}_{\mathbf{t}}$, based on the appropriate information set, assuming that $\overline{\boldsymbol{\mu}}, \mathbf{F}, \mathbf{R}$, and $\mathbf{Q}^{*}$ are known. ${ }^{13}$ In other words, it provides a minimum mean square error estimate of $\mathbf{B}_{\mathbf{t}}$, given the appropriate information set. Depending upon the information set used, it is possible to find the basic filter and the smoothing filter. The former refers to an estimate of $\mathbf{B}_{\mathbf{t}}$ based on information available up to time $t$, whereas the latter refers to an estimate of $\mathbf{B}_{\mathbf{t}}$ based on all the available information in the sample through time $T$.

The basic filtering consists of two steps: the prediction step and the updating step. These can be represented by the following equations, where equations (A.8) to (A.11) depict the prediction step, and equations (A.12) and (A.13) depict the updating step:

$$
\begin{aligned}
& \mathbf{B}_{\mathrm{t} \mid \mathrm{t}-1}=\overline{\boldsymbol{\mu}}+\mathrm{FB}_{\mathrm{t}-1 \mid \mathrm{t}-1} \\
& \mathbf{P}_{\mathbf{t} \mid \mathbf{t}-\mathbf{1}}=\mathbf{F} \mathbf{P}_{\mathbf{t}-\mathbf{1} \mid \mathrm{t}-\mathbf{1}} \mathbf{F}^{\prime}+\mathbf{Q} \\
& \eta_{t \mid t-1}=y_{t}-y_{t \mid t-1}=y_{t}-H_{t} B_{t \mid t-1}-A z_{t} \\
& \mathbf{f}_{\mathrm{t} \mid \mathrm{t}-\mathbf{1}}=\mathbf{H}_{\mathrm{t}} \mathbf{P}_{\mathbf{t} \mid \mathbf{t}-\mathbf{1}} \mathbf{H}_{\mathrm{t}}^{\prime}+\mathbf{R} \\
& B_{t \mid t}=B_{t \mid t-1}+K_{t} \eta_{t \mid t-1} \\
& \mathbf{P}_{\mathrm{t} \mid \mathrm{t}}=\mathbf{P}_{\mathrm{t} \mid \mathrm{t}-\mathbf{1}}-\mathbf{K}_{\mathrm{t}} \mathbf{H}_{\mathrm{t}} \mathbf{P}_{\mathrm{t} \mid \mathrm{t}-\mathbf{1}}
\end{aligned}
$$

where $\mathbf{K}_{\mathbf{t}}=\mathbf{P}_{\mathbf{t} \mid \mathbf{t}-\mathbf{1}} \mathbf{H}_{\mathbf{t}}^{\prime} \mathbf{f}_{\mathbf{t} \mid \mathbf{t}-\mathbf{1}}^{-\mathbf{1}}$ is the Kalman gain, which determines the weight assigned to new information about $\mathbf{B}_{\mathbf{t}}$ contained in the prediction error, $\boldsymbol{\eta}_{\mathbf{t} \mid \mathbf{t}-\mathbf{1}} ; \mathbf{B}_{\mathbf{t} \mid \mathbf{t}-\mathbf{1}}$ and $\mathbf{B}_{\mathbf{t} \mid \mathbf{t}}$ are the expectations (estimates) of $\mathbf{B}_{\mathbf{t}}$ conditional on information up to $t-1$ and $t$, respectively; $\mathbf{P}_{\mathbf{t} \mid \mathbf{t}-\mathbf{1}}$ and $\mathbf{P}_{\mathbf{t} \mid \mathbf{t}}$ are the covariance matrices of $\mathbf{B}_{\mathbf{t}}$ conditional on information up to $t-1$ and $t$, respectively; $\mathbf{y}_{\mathbf{t} \mid \mathbf{t}-\mathbf{1}}$ is the forecast of $\mathbf{y}_{\mathbf{t}}$ given information up to $t-1$; and $\mathbf{f}_{\mathbf{t} \mid \mathbf{t}-\mathbf{1}}$ is the conditional variance of the prediction error.

On the other hand, the smoothing filter provides a more accurate inference on $\mathbf{B}_{\mathbf{t}}$ since it uses more information than the basic filter. For $t=T-1, T-2, \ldots, 1$, the smoothing filter can be described by the following equations:

\footnotetext{
${ }^{13}$ It is also possible to employ Generalized Least Squares regressions. However, this method may be extremely inefficient in terms of its computational burden (see Kim and Nelson 1999).
} 


$$
\begin{aligned}
& \mathbf{B}_{\mathbf{t} \mid \mathbf{T}}=\mathbf{B}_{\mathbf{t} \mid \mathbf{t}}+\mathbf{P}_{\mathbf{t} \mid \mathbf{t}} \mathbf{F}^{\prime} \mathbf{P}_{\mathbf{t}+\mathbf{1} \mid \mathbf{t}}^{-1}\left(\mathbf{B}_{\mathbf{t}+1 \mid \mathbf{T}}-\mathbf{F B}_{\mathbf{t} \mid \mathbf{t}}-\overline{\boldsymbol{\mu}}\right) \quad \ldots \ldots \ldots \ldots \ldots \\
& \mathbf{P}_{\mathbf{t} \mid \mathbf{T}}=\mathbf{P}_{\mathbf{t} \mid \mathbf{t}}+\mathbf{P}_{\mathbf{t} \mid \mathbf{t}} \mathbf{F}^{\prime} \mathbf{P}_{\mathbf{t}+1 \mid \mathbf{t}}^{-1}\left(\mathbf{P}_{\mathbf{t}+1 \mid \mathbf{T}}-\mathbf{P}_{\mathbf{t}+1 \mid \mathrm{t}}\right) \mathbf{P}_{\mathbf{t}+1 \mid \mathbf{t}}^{-1} \mathbf{F P}_{\mathbf{t} \mid \mathbf{t}}^{\prime} \ldots \cdots \cdots \quad \text { (A. 15), }
\end{aligned}
$$

where the initial values for the smoothing, $\mathbf{B}_{\mathbf{T} \mid \mathbf{T}}$ and $\mathbf{P}_{\mathrm{T} \mid \mathbf{T}}$, are obtained from the last iteration of the basic filter.

Finally, it is possible to use the sample log likelihood function based on the prediction error decomposition to estimate the model's unknown parameters. If both the prediction error $\left(\boldsymbol{\eta}_{\mathbf{t} \mid \mathbf{t}-1}\right)$ and the variance $\left(\mathbf{f}_{\mathbf{t} \mid \mathbf{t}-\mathbf{1}}\right)$ of the state-space model are estimated via the Kalman filter and if the observations are normally distributed, then the sample log likelihood function for a stationary $\mathbf{B}_{\mathbf{t}}$ in (A.2), $L$, is represented by:

$$
L=-\frac{1}{2} \sum_{t=1}^{T} \ln \left(2 \pi \mathbf{f}_{\mathbf{t} \mid \mathbf{t}-\mathbf{1}}\right)-\frac{1}{2} \sum_{t=1}^{T} \boldsymbol{\eta}_{\mathbf{t} \mid \mathbf{t}-\mathbf{1}}^{\prime} \mathbf{f}_{\mathbf{t} \mid \mathbf{t}-\mathbf{1}}^{-1} \boldsymbol{\eta}_{\mathbf{t} \mid \mathbf{t}-\mathbf{1}} \quad \ldots \ldots \ldots \ldots \text { (A. 16), }
$$

which can be maximized with respect to the unknown parameters of the model. 


\section{Appendix B: Tables}

Table B.1. USA: Estimated parameters obtained from equations (2), (3) and (5)

\begin{tabular}{|c|c|c|c|}
\hline \multirow[t]{2}{*}{ Parameters } & \multirow[t]{2}{*}{$\begin{array}{c}\text { Nonfarm business sector, } \\
1947-2016^{\mathrm{a}, \mathrm{c}}\end{array}$} & \multicolumn{2}{|c|}{$\begin{array}{l}\text { Nonfinancial corporate business sector, } 1948- \\
2015^{\mathrm{b}, \mathrm{c}}\end{array}$} \\
\hline & & $\begin{array}{l}\text { Using the unadjusted } \\
\text { labor share }\end{array}$ & $\begin{array}{c}\text { Using the adjusted labor } \\
\text { share }\end{array}$ \\
\hline \multirow{2}{*}{$\alpha_{0}$} & 27.599 & $-92.700 * *$ & $-96.597 * *$ \\
\hline & $(28.857)$ & $(45.763)$ & $(39.022)$ \\
\hline \multirow[b]{2}{*}{$\alpha_{1}$} & $1.071 * * *$ & $1.146^{* * *}$ & $0.897 * * *$ \\
\hline & $(0.168)$ & $(0.265)$ & $(0.271)$ \\
\hline \multirow[b]{2}{*}{$\alpha_{2}$} & $0.403 * * *$ & $0.305^{* * *}$ & $0.256^{* * *}$ \\
\hline & $(0.086)$ & $(0.057)$ & $(0.059)$ \\
\hline \multirow[b]{2}{*}{$\alpha_{3}$} & -0.004 & -0.161 & 0.034 \\
\hline & $(0.167)$ & $(0.198)$ & $(0.131)$ \\
\hline \multirow{2}{*}{$\alpha_{4}$} & $-0.275 * * *$ & $-0.139 *$ & -0.076 \\
\hline & $(0.072)$ & $(0.083)$ & $(0.103)$ \\
\hline \multirow{2}{*}{$\beta_{0}$} & -105.467 & 317.937 & 257.900 \\
\hline & $(66.989)$ & $(227.301)$ & $(241.646)$ \\
\hline \multirow{2}{*}{$\beta_{1}$} & -0.338 & -0.733 & -0.407 \\
\hline & $(0.381)$ & $(0.689)$ & $(0.605)$ \\
\hline \multirow{2}{*}{$\beta_{2}$} & $0.594 * * *$ & $0.495 * *$ & $0.628 * * *$ \\
\hline & $(0.200)$ & (0.193) & $(0.201)$ \\
\hline \multirow{2}{*}{$\beta_{3}$} & -0.015 & 0.260 & 0.403 \\
\hline & $(0.400)$ & $(0.823)$ & $(0.664)$ \\
\hline \multirow{2}{*}{$\beta_{4}$} & -0.121 & 0.001 & -0.088 \\
\hline & $(0.198)$ & $(0.283)$ & $(0.335)$ \\
\hline \multirow{2}{*}{$\sigma_{\psi}$} & $1.036 * * *$ & $0.756 * * *$ & $0.833 * * *$ \\
\hline & $(0.143)$ & (0.110) & $(0.115)$ \\
\hline & $2.233^{* * *}$ & $2.958 * * *$ & $3.143^{* * *}$ \\
\hline$\sigma_{v}$ & $(0.325)$ & $(0.421)$ & $(0.492)$ \\
\hline$L^{\mathrm{d}}$ & -268.929 & -259.708 & -268.328 \\
\hline
\end{tabular}

Notes: ${ }^{T}$ The labor share included in the state-space model corresponds to an index, $2009=100$; 'The labor share included in the state-space model was measured in percentage; 'Standard errors are shown in parenthesis; 'Log-likelihood.

$*, * *$, and $* * *$ denote statistical significance at the $10 \%, 5 \%$ and $1 \%$ levels, respectively. 
Table B.2. USA: Estimated parameters obtained from equations (2), (3) and (6)

\begin{tabular}{|lcc|}
\hline \hline Parameters & $\begin{array}{c}\text { Nonfarm business sector, } \\
1947-2016^{\mathrm{a}, \mathrm{c}}\end{array}$ & $\begin{array}{c}\text { Nonfinancial corporate business } \\
\text { sector using the unadjusted labor } \\
\text { share, } 1948-2015^{\mathrm{b}, \mathrm{c}}\end{array}$ \\
\hline$\gamma_{0}$ & 34.780 & -85.118 \\
$\gamma_{1}$ & $(26.453)$ & $(53.654)$ \\
& 0.026 & 0.187 \\
$\gamma_{2}$ & $(0.178)$ & $(0.217)$ \\
& $0.399^{* * *}$ & $0.308^{* * *}$ \\
$\gamma_{3}$ & $(0.074)$ & $(0.054)$ \\
& 0.039 & 0.019 \\
$\gamma_{4}$ & $(0.146)$ & $(0.112)$ \\
& $-0.269^{* * *}$ & $-0.156^{*}$ \\
$\zeta_{0}$ & $(0.078)$ & $(0.080)$ \\
& $-119.913^{*}$ & 232.174 \\
$\zeta_{1}$ & $(61.958)$ & $(193.009)$ \\
& -0.245 & -0.445 \\
$\zeta_{2}$ & $(0.312)$ & $(0.678)$ \\
& $0.661^{* * *}$ & $0.663^{* * *}$ \\
$\zeta_{3}$ & $(0.140)$ & $(0.159)$ \\
& -0.320 & -0.195 \\
$\zeta_{4}$ & $(0.250)$ & $(0.469)$ \\
& -0.109 & -0.077 \\
$\sigma_{\Delta \psi}$ & $(0.197)$ & $(0.325)$ \\
$\sigma_{v}^{\prime}$ & $1.017^{* * *}$ & $0.772^{* * *}$ \\
$L^{\mathrm{d}}$ & $(0.140)$ & $(0.121)$ \\
\hline \hline
\end{tabular}

Notes: ${ }^{a}$ The labor share included in the state-space model corresponds to the first differences of the labor share index, 2009=100; ${ }^{\text {b}}$ The labor share included in the state-space model corresponds to the first differences of the labor share measured in percentage; 'Standard errors are shown in parenthesis; ${ }^{d}$ Loglikelihood.

$*, * *$, and $* * *$ denote statistical significance at the $10 \%, 5 \%$ and $1 \%$ levels, respectively. 